\title{
Learning Style and Academic Performance of First Year Agricultural Undergraduates: A Case in Rajarata University of Sri Lanka
}

\author{
S.M.C.B. Karalliyadda ${ }^{1}$ \\ Received: $6^{\text {th }}$ May 2016 / Accepted: $7^{\text {th }}$ September 2016
}

\begin{abstract}
In Sri Lankan universities, lecturers are trained and requested to conduct learning style assessments to design strategies for better educational environments. Even though, limited attention has been acquired in the area of learning styles and academic performances, less literature is found related to agricultural undergraduates. This study has attempted to investigate the learning styles of first year agricultural undergraduates in one of the Sri Lankan universities. The objective was thereby, to examine any association between learning styles and academic performances. A Cross sectional survey was administered using a structured questionnaire consisting of the VARK learning style tool. Results illustrated that most of the students have multimodal learning styles and, those styles were independent from gender or their high school academic discipline pertaining to agriculture or biology. Among these learning styles, kinesthetic style has gained a reasonable attention. The study concluded no substantial association between learning styles and academic performances. Availability of multimodal learning styles are suitable to use blended teaching aids such as lectures, video and illustrations as well as to encourage students to take self-notes etc. Moreover, facilitating each student to gain hand on experience can be used to enhance the learning. Finally, this study can also be performed using some other available methods to avoid the biased errors and to understand the learning styles in different angles.
\end{abstract}

Keywords: Learning Style, Academic Performance, Undergraduates

\section{INTRODUCTION}

In Sri Lanka, secondary education is a highly teacher oriented system. Students, who have entered to the university system, have undergone this process for almost 13 years. As a final evaluation of this process, students have to undertake "General Certificate in Education (GCE), Advanced Level Examination" demonstrating the academic momentum of Sri Lankan students. Additionally, students must successfully pass the ambitious national examination to enter the Sri Lankan national universities. In the year 2014, total university admissions for undergraduate programs were 25,200 (University Grant Commission 2014), $10.2 \%$ of the total candidates (Central Bank of Sri Lanka 2014). In order to pursue most of the national universities, students should have undertaken either Biology and /or Agriculture as a compulsory prerequisite in their advanced level program.

Following the enrolment of in an agricultural degree program, undergraduates are exposed to an academic environment where all the academic lessons, practical sessions, and evaluations are conducted comparatively different to their previous high school backgrounds. Though the Sri Lankan languages of Sinhala or Tamil were the basic communication media at high school, English is the primary communication media of the agriculture degree programs in these universities. 
In such conditions, academic performances of students at the universities tend to vary due to many direct and indirect reasons. A study conducted at the Faculty of Agriculture, University of Ruhuna has identified that students those who use computers and library for academic purposes, frequently attend lectures, prepare short notes and prefer to study alone, have a higher tendency to obtain better results. Interestingly, their proficiency of the English language is also better than those who have low academic performances. (Sandika et al., 2012).

Similarly, a study conducted by the Faculty of Agriculture, University of Peradeniya, revealed that English language proficiency, academic effort, and family background as main components of academic performance at any level of undergraduate degree program (Weerahewa et al., 2012) .

In the national universities, lecturers who instruct undergraduate students are being guided to take part in a teacher induction program in order to provide better educational services for the undergraduate students. As a learning outcome of this induction program lecturers are given instructions to identify learning styles of the students to select or to design suitable teaching and learning strategies, which can cater to the learning demands of students (University grant commission Sri Lanka, 2012).

\section{Learning Styles}

The "learning styles" are basically aimed at the ways of learning of individuals. There are many models to explain the learning style in a given context. According to the concept of Experiential Learning, people gain knowledge by transforming their experiences. During the learning process Kolb has explained that this concept follows two approaches (Concrete experience/Abstract conceptualization) to absorb the experiences and two approaches (Reflective observation/Active experimentation) to transform the experiences into learning and identified four learning styles (Accommodator/ Converger /Diverger /Assimilator) based on different combinations of these approaches. (Kolb, 2014)

Another learning model identified that learning style as unique factor of an individual, while other styles remain moderate or low levels. These learning styles are shaped by 18 different elements and those have been categorized into four main sections such as environmental, sociological, emotional and physical. Environmental elements consist of sound, light, temperature and design of the learning area. According to the sociological elements, individuals' learning styles differ when learners are either alone or with adults, peers or related combination of those. This model has explained that emotional factors as motivation, persistence, responsibility and structure. The model has finally and especially explained, perceptual strength (visual, auditory, kinesthetic, etc) as one single element under physical category. Other than that intake, time and the mobility of the individual also belongs to this category. (Dunn and Dunn, 1979).

Another study explained that learning style as an acquired process of repetition or will. In this process, it has defined four learning styles based on four stages of the learning process such as activist (having experience), reflector (reviewing the experience), theorist (concluding from the experience) and pragmatist (planning the next steps) (Honey and Mumford 1992).

Neil Fleming defines the learning as the desired method of getting information, which is best and unique to a person (VARK Learn Limited, 2015). According to his explanations, students learn about their environment by four main different learning styles. He has defined these styles as 'VARK' which is designed to elaborate Visual, Aural, Read/Write and Kinesthetic terms (Fleming, and Baume, 2006). People who prefer to learn by ear are being named as 'Aural' learners and those who prefer to access 
information by written or printed materials are known as 'Read and Write' learners whilst the "Visual" learners prefer and learn best when they are given with pictorial information. Similarly, 'Kinesthetic' learners like to learn from their experiences (Fleming, 1995).

Effective learning will be taken place if prior analysis of learning preference of the learners is done and instructions are designed accordingly (Pashler et al., 2008). But if the classroom environment facilitates only one single learning style, it will hinder the learning of other students. These mismatches between the learning and teaching style can create consequences in the learning environments. Therefore, it is important to identify the learning styles of learners to develop the best instructional methods for better education.

Though the impact of learning style is highly recognized, identification of undergraduates' learning styles have only been recognized by a few Sri Lankan studies and the target student groups were mainly from medical science disciplines (Samarakoon, et al., 2013; Dissanayaka, 2014; Bataduwaarachchi, et al., 2013). Thus, the main objective of the study was to identify the learning styles and its impact on the academic performance of first year agricultural undergraduates at the Faculty of Agriculture, Rajarata University of Sri Lanka.

\section{MATERIALS AND METHODS}

This study was conducted among the first year undergraduates of the Faculty of Agriculture, in Rajarata university of Sri Lanka. A Cross sectional analysis was carried out from the data collected voluntarily from 74 students out of 94 after explaining the purpose.

The first section of the questionnaire was administered to collect information about gender, academic stream of the students' advanced level program in their high school
(Agriculture or Biology), and first year academic performance as grade point average (GPA) of the semester examination. Second section of the questionnaire consisted with the printed form of the VARK questionnaire version 7.8 (2014). In the VARK questionnaire, sixteen (16) questions were included having four answering possibilities for each question. Each question was related to usual day to day activities and each answering decision has been designed to correlate with a learning style preference. Permission to the VARK questionnaire was obtained from the copyright holder \{ (C) copyright Version 7.8 (2014) held by VARK Learn Limited, Christchurch, New Zealand\}.

As this questionnaire allows a respondent to select one or more answering options for each question, different learning style combinations (multiple learning styles) were possible. Since questions related to situations of day to day activities, respondents were able to freely express their normal response(s) for those given situations. If respondents identified any question which was not related to their personal experiences, they would be free to leave it without any response. Each questionnaire was evaluated based on a scoring chart which was previously validated (VARK Learn Limited, 2015).

Data was entered in a spreadsheet and imported to SPSS 22 for the analysis. Learning styles of the students were identified using descriptive statistics. Those who obtained the highest scores by indicating only one option for each question were recognized as Unimodal learners, whereas students who indicated two, three or four combinations of options were identified as Bimodal, Trimodal and Quadrimodal learners respectively. A Chi-Square test was carried out to identify the significant difference of the learning styles between attributes 1: between male and female student 2: Students either who followed biology or agriculture in their advanced level programs. Finally, One-way ANOVA test 
was administered to identify the availability of significant academic performance differences between the learning styles.

\section{RESULTS AND DISCUSSION}

During the data collection period, all the respondents were following their first year, second semester in their university academic program. Accordingly, this sample consisted of both males $(31 \%)$ and females $(68.9 \%)$. The majority $(76 \%)$ of the students have followed Biology, whereas others have followed Agriculture (24\%) as their academic streams in advanced level program.

\section{Learning styles}

University is a community consisted of teachers and scholars, where universal education takes place. Therefore, undergraduate level education imparts the most important fundamentals to improve intellectual capacities of students. In universities, agriculture education is one of the subjects which has high theoretical, practical, and field based components. Students learn the best when they are provided with suitable educational environments during their learning. Accordingly, it is important for the Lecturers/ Instructors to recognize the learning styles of their students.

VARK analysis of the learning styles has indicated that the majority $(89 \%)$ of students were multimodal learners. Interestingly, among multimodal learners, Quadrimodal learning style (58\%) was significant. Kinesthetic learners $(88 \%)$ were prominent among Unimodal learners, whereas among Bimodal learners, combination of Auditory and Kinesthetic learners $(53 \%)$ were prominent. Similarly, among Trimodal learners, combination of Visual, Reading and Kinesthetic modes (50\%) were prominent (Table 01).Interestingly, Kinesthetic learning style has obtained a portion in each main learning style category and sub category. . This shows that all of the students have a slight or significant preference to learn by experiencing.

Findings of the study further elaborate that, the majority $(89 \%)$ of the students perform the multimodal learning style, which is a collection of learning styles such as Bimodal, Trimodal and Quadrimodal) rather than one single learning style (Unimodal).Similarly, these results agree with the findings of the other studies (Zeynep\&Melis, 2007; Urval et al., 2014; Kanchi et al., 2013; Loulwa, 2013; Turky\& Almigbal, 2015) among medical science undergraduates. Victor (2011) did a similar study among the students at the Faculty of Science and Agriculture, the University of the West Indies and concluded that most of the students show similar characteristics as depicted in the above studies. In his finding he also explained learning styles are independent with age and gender of the students.

Table 01: Learning styles according to the VARK test

\begin{tabular}{cccc}
\hline Unimodal & & Multi-modal & Quadrimodal \\
\hline $11 \%$ & Bimodal & Trimodal & $58 \%$ \\
$($ Visual-12\%) & (Visual \& Reading-6\%) & (Auditory, Reading \& Kinesthetic-17\%) & \\
& (Visual \& Kinesthetic-29\%) & (Visual, Auditory \& Kinesthetic-33\%) & (Visual, \\
& Auditory, \\
Reading \& \\
(Kinesthetic-88\%) & (Auditory \& Kinesthetic-53\%) & & Kinesthetic) \\
& (Reading \& Kinesthetic-12\%) & (Visual, Reading \& Kinesthetic-50\%) & \\
\hline
\end{tabular}


From multimodal learning style, most of the students (58\%) showed the Quadrimodal learning style. This means that the majority of the students have an ability of learning through different means, such as videos, books, lectures, practical sessions and etc. This is a very positive indicator for instructors because in a university environment there are many resources available for the students to learn their academic and general life matters. Therefore, students may capture their learning needs by those various materials rather depending on one single source. Similarly, instructors can freely arrange a variety of teaching programs including a mixture of teaching aids such as classroom lectures, video presentations, reading assignments, and practical lessons in their course curricula.

The majority $(88 \%)$ of the students, who preferred Unimodal learning style indicated that they prefer a Kinesthetic learning style. In other categories as well, appearance of kinesthetic style indicates students' preference of learning by experience. This finding is also a positive fact for agricultural undergraduates as their degree program has a significant portion of practical and field applications. When students get hands on experience about their theoretical aspects, having kinesthetic learning style will support them to learn best while exploring their skills in real life situations.

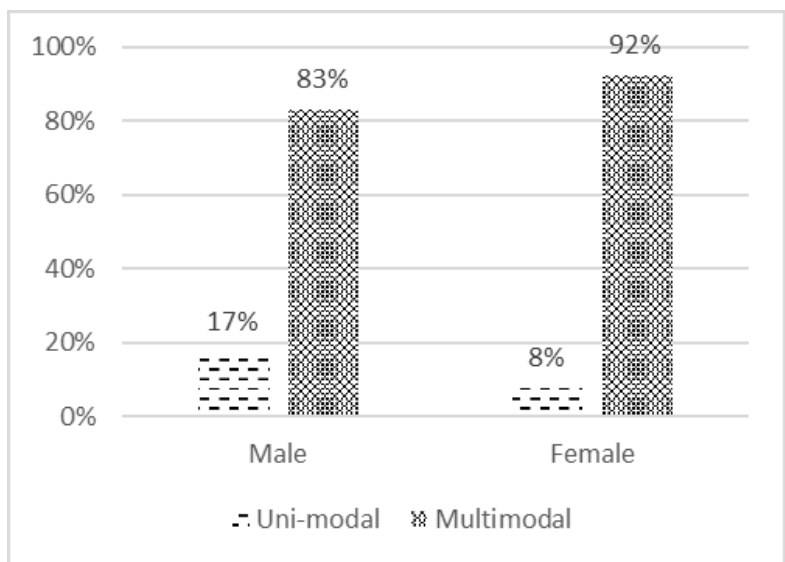

Figure 01: Distribution of learning styles among gender

\section{Influence of gender on major learning styles}

In this research Unimodal and Multi-modal learning styles were considered as the two main learning styles. Among the students, the majority of female (92\%) and male (83\%) students indicated multimodal as their preferred learning style (figure 01). According to the results of the Chi-Square analysis, there was no significant difference between two groups $(p<0.05)$.

Among the male and female students of this sample, it indicated higher preferences for multimodal learning style and there were no significant differences between genders on learning styles. This study supports most of the arguments that gender has no significant influence on learning styles (Zeynep\&Melis, 2007; Urval et al., 2014; Loulwa, 2013; Victor, 2011; Turky\&Almigbal, 2015).

\section{Influence of previous academic discipline on learning style}

Even though students entered to follow the agriculture degree program after following either biology stream or agriculture stream, learning style is independent from such academic streams. Therefore, it can be concluded that the governing factors of the learning style exclude $(p<0.05)$ previous academic backgrounds.

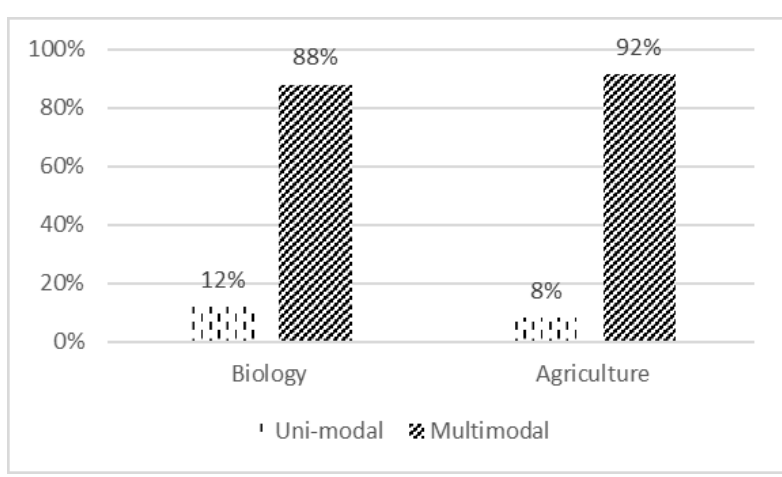

Figure 02: Distribution of learning style vs students' main advanced level disciplines 
Impact of learning style on academic performance

One -way ANOVA test was administered to identify significant differences of academic performances among the students who showed different learning styles. Descriptive statistics of the academic performance is given in the table 02. Unimodal learning style group had the highest mean GPA (2.8317), whereas Trimodal learning style group showed the lowest mean GPA (2.4383).

In the first and second year after entering the university, students have to follow core subjects of the agricultural degree program. Cumulative achievement of the continuous evaluations and final evaluations is the base of academic performance. After completing the end semester examination, marks are given as a GPA. In this study, students had different GPAs from 1.81 to 3.54 , and the mean GPA was 2.7112. Bimodal learning style group had highest mean GPA (2.8317), whereas Trimodal learning style group showed lowest mean GPA
(2.4383), whereas none of the learning style groups showed significant statistical association with the grade point average. This supports the argument raised by two studies conducted among medical and agricultural undergraduates (Victor, 2011; Turky \& Almigbal, 2015), that academic performances of the students are not related with their learning styles. But contradictory findings of Loulwa (2013) indicates that there is an association between the learning styles and academic performances of the undergraduate students. According to the Victor (2011) suggestions, this insignificant relationship between learning styles and academic performance could be as a result of inability of VARK analysis to understand students' actual learning. In the same way some researchers have suggested that this learning style could not be the best way to learn. Even though they prefer one modality, they may have adapted to other learning modalities (Loulwa, 2013) with their long period of education or real life experiences. Therefore, identifying one's current learning style is not an ending point.

Table 02: Students' mean GPA scores of different learning styles

\begin{tabular}{crrrr}
\hline Learning Style & Mean GPA & Std. Deviation & Minimum & Maximum \\
\hline Uni-modal & 2.6320 & .57946 & 2.15 & 3.54 \\
Bimodal & 2.8317 & .52108 & 1.81 & 3.39 \\
Tri modal & 2.4383 & .49604 & 1.87 & 3.11 \\
Quadri modal & 2.7338 & .34452 & 2.10 & 3.24 \\
Total & 2.7112 & .43763 & 1.81 & 3.54 \\
\hline
\end{tabular}

Table 03: One-way ANOVA for significant GPA differences between learning style groups

\begin{tabular}{lrrrrr} 
& \multicolumn{1}{c}{ Sum of Squares } & df & Mean Square & \multicolumn{1}{c}{ F } & Sig. \\
\hline Between Groups & .666 & 3 & .222 & 1.171 & .331 \\
Within Groups & 8.528 & 45 & .190 & & \\
Total & 9.193 & 48 & & & \\
\hline
\end{tabular}

According to the findings of one-way ANOVA, existence of possible differences between the means among four learning styles were not significant as shown in table $03 . \mathrm{F}(3,45)=1.171, \quad \mathrm{p}>0.05$. 
According to Flemings understanding of learning style, it creates a catalyst to empower students to reflect their own sensory preferences. Therefore, once students become aware of their learning style they would modify their study methods accordingly (Fleming \& Mills 1992).

\section{CONCLUSIONS AND RECOMMENDATIONS}

Predetermination of student learning style would be an added advantage for instructors. Then instructions, instructional aid and the environment could be developed to suit the demands and interests of the learners. In this study many students had at least two learning combinations (multimodal learning). This means that students are more preferred to learn when there are different learning ways. Therefore, university agricultural instructional mechanisms should consist of a variety of teaching methods rather than depending on lectures. Even the lecture should be designed to satisfy the learners learning style by including visual explanations, practical sessions, reading exercises and encouraging them to make own notes. Interestingly, each of the unimodal and multimodal categories had a significant portion of kinesthetic learning style preference which is a good sign for agriculture study programs. Therefore, in each practical session it is better if each student should be given appropriate time to get the hands-on experience. If time or resources are limited, teaching schedules and programs should be designed to give the opportunity to acquire real experience of the subject matters.

Student who had bimodal learning styles showed the highest mean academic performance. But none of the identified learning styles by VARK method showed a significant relationship with the academic performance. Since these learning styles were tested with only one method, it might have certain limitations. Sometimes, it is possible that students may use different methods like cramming just before the examination even they cannot learn a thing. Moreover, even students learned on their preferred learning styles, they might not have been able to perform well in the examinations due to certain other factors like low English competency to translate their learned subject matters, or limited time management ability, knowledge processing ability or etc,.

However, it is not suitable to justify that learning styles do not affect students' academic performances. Therefore, this study suggests future studies to investigate students' learning styles based on other recognized methods and also to investigate the relationship of those to the academic performance. At the same time it is better to understand the students' knowledge processing and transforming mechanisms in each preferred learning style.

\section{REFERENCES}

Bataduwaarachchi, V.R., Dissanayake, M.M., Thillainathan, S., Jayasekara, R.W., Baykan, Z., Naçar, M. (2013). Perception of the learning strategies and the learning styles among first year medical students: A cross sectional survey, South-East Asian Journal of Medical Education, 07, 01, pp. 14-21.

Central Bank Sri Lanka. (2014) Annual Report 2014, Key Economic Indicators. Retrieved from http://www.cbsl.gov.lk/pics_n_docs/10_pub/_docs/efr/annual_report/AR2014/ English/4_ KSI.pdf 
Dissanayaka, T.D. (2014). The learning styles and the preferred teaching learning strategies of first year physiotherapy students, International Journal of Scientific and Research Publication, 04, 07,pp.1-3

Dunn,R.S and Dunn,K.J (1979). Learning styles/Teaching styles; should they.,can they. Be matched? Educational Leadership, 36, 04, pp.235-244.

Fleming, N. D. \& Mills, M. (1992).Not Another Inventory, Rather a Catalyst for Reflection,To Improve the Academy, ,pp. 137-155. Retrieved from http://digital commons.unl.edu/cgi/ viewcontent.cgi? article $=1245 \&$ context $=$ podimproveacad

Fleming, N., and Baume, D. (2006) Learning Styles Again: VARKing up the right tree!,Educational Developments,7.4,pp.04-07,Retrieved from http://www.seda.ac.uk/resources/files/ publications_17_eddev7_4.pdf.

Fleming, N.D. (1995). I'm different; not dumb. Modes of presentation (VARK) in the tertiary classroom, in Zelmer,A., (Ed.) Research and Development in Higher Education, Proceedings of the 1995 Annual Conference of the Higher Education and Research Development Society of Australasia (HERDSA) Vol18, pp. 308 - 313.Australia: HERDSA.

Kanchi, S., Junaid, A., Nandita, S., Srikant, N. (2013). How different are students and their learning styles? International Journal of Research in Medical Sciences, 01, 03,pp. 212-215.

Kolb, D. A. (2015) [1984]. Experiential learning: experience as the source of learning and development (2nd ed.). Upper Saddle River, NJ: Pearson Education. ISBN 9780133892406. OCLC 909815841.

Loulwa, Mohammed S.A (2013).Learning style preference of first-year dental students at King Saud University in Riyadh, Saudi Arabia: Influence of gender and GPA, Journal of Dental Education, 77, 10, pp.1371-1378.

Pashler, H., McDaniel, M., Rohrer, D. \& Bjork, R. (2008). Learning Styles: Concepts and Evidence. Psychological Science in the Public Interest, 09, 03,pp.106-119.http://www. psychologicalscience.org/index.php/publications/journals/pspi

Samarakoon, L., Fernando, T., Rodrigo, C. \&Rajapakse, S. (2013). Learning styles and approaches to learning among medical undergraduates and postgraduates, BMC Medical Education, 13, 42.doi:10.1186/1472-6920-13-42 https:/doi.org/10.1186/1472-6920-13-42

Sandika,A.L., Atapattu,N.S.B.M. \&Weerasinghe, W.M.C.B. (2012). Factors affecting the academic performance of agriculture undergraudates: a case in faculty of agriculture, university of Ruhuna, SAARC journal of educational research, 9, pp.1-13.

Turky H. \&Almigbal, T.H. (2015). Relationship between the learning style preferences of medical students and academic achievement, Saudi Medical Journal, 36, 3, pp.349-355.

University grant commission Sri Lanka. (2012). Induction Program for Academic Staff of Sri Lankan Universities, Training Manual No: CPD/Academic/04.Retrieved from http://www. ugc.ac.lk/attachments/Training\%20manual\%20on\%20induction $\% 20$ programme $\% 20$ for $\% 20$ academic $\% 20$ staff $\% 20$ of $\% 20$ Sri\%20Lankan\%20Universities.pdf 
University Grants Commission. (2014). University statistics 2014, 2. Retrieved from http://www. ugc.ac.1k/downloads/statistics/stat_2014/Chapter\%202.pdf

Urval, R.P., Kamath, A., Ullal, S., Shenoy, A.K., Shenoy, N., Udupa,L.A. (2014).Assessment of learning styles of undergraduate medical students using the VARK questionnaire and the influence of sex and academic performance, Advances in Physiology Education, 38, 03, pp.216-220. https:/doi.org/10.1152/advan.00024.2014

VARK Learn Limited. (2015). vark-learn.com. Retrieved July 20, 2015, http://vark-learn.com/.

Victor, M. (2011). An analysis of some factors affecting student academic performance in an introductory biochemistry course at the University of the West Indies, Caribbean Teaching Scholar, 1, 2, pp.79-92.

Weerahewa,J., Bulathwela,S., Silva,P., \&Perera, K. (2012). An analysis of academic performance of undergraduates: Effect of academic vis-à-vis non-academic factors, Peradeniya University Research Sessions PURSE - 2012, Book of Abstracts, University of Peradeniya, Sri Lanka, 17, 29. Retrieved from http://dlib.pdn.ac.lk/handle/1/3853.

Zeynep, B. \& Melis, N. (2007).Learning styles of first-year medical students attending Erciyes University in Kayseri, Turkey, Advances in Physiology Education, 31, 02, pp.158-160. https:/doi.org/10.1152/advan.00043.2006 